\title{
$\square$ - Reinaldo Moura e a modernidade em Porto Alegre
}

\section{MaRgot InÊs VilLas Boas CaRUCCIO}

Arquiteta, mestra e pesquisadora da Faculdade de Arquitetura (FARQ) da Universidade Federal do Rio Grande do Sul (UFRGS).

Resumo: Trata-se de estudar a história da arquitetura de Porto Alegre através da obra de ficção literária. $O$ escritor em foco é Reynaldo Moura, um jornalista de Santa Maria (Rio Grande do Sul). Autor de novelas intimistas, Moura observa, através de descrições de cenários literários, a arrebatadora transformação da cidade provinciana em uma moderna capital do século XX.

Palavras-chave: modernidade; Porto Alegre; literatura gaúcha; cidade; arquitetura
Abstract: This article discusses the possibility of studying the history of Porto Alegre's architecture through literary fiction. The writer under study is Reynaldo Moura, a journalist from Santa Maria ( Rio Grande do Sul) who wrote intimist novellas. Through his descriptions of literary settings, he demonstrates the fascinating transformation of the provincial town into a modern capital city in the first half of the 20th century.

Key-word: modernity; Porto Alegre; gaucha literature; city; architecture 


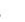


Muitos acreditam que a representação da arquitetura esteja restrita apenas a métodos gráficos ou tridimensionais. Parto do princípio de que ela pode ser representada de outras formas. No caso específico da literatura de ficção, a arquitetura pode estar representada na descrição dos ambientes verdadeiros ou imaginários de um determinado texto literário. Estudar a história da cidade de Porto Alegre mais precisamente, a modernidade, através da literatura ficcional é, em primeiro lugar, um deleite para quem reconhece a importância da ficção literária para a história de uma cultura, de um povo. Reconhecer este processo interdisciplinar, amálgama de literatura, história, sociologia, arquitetura e urbanismo, é o objetivo deste artigo. Dentre outros escritores importantes para a história da literatura do Rio Grande do Sul encontramos a figura de Reynaldo Moura, destacando-se na produção de uma obra intimista e realista em uma época de valorização do chamado "regionalismo literário".

Nascido na cidade de Santa Maria, em 1900, o escritor Reynaldo Moura chega, aos oito anos de idade, a Porto Alegre. Estuda medicina, química, direito, mecânica e comércio, sem, no entanto, concluir nenhum desses cursos. Graduado em jornalismo pertenceu à redação de jornais importantes da capital, como o Diário de Notícias e o Jornal da Manhã. Redator político de A Federaçâo, colaborou, como cronista, para algumas revistas nacionais, até 1965, ano de seu falecimento.

Pouco conhecido nos meios acadêmicos, escreveu as seguintes novelas: A Ronda dos Anjos Sensuais (1935), Noite de Chuva em Setembro (1939), Intervalo Passional (1944) Um Rosto Noturno (1946), O Poder da Carne (1954), O Romance no Rio Grande (1958), A Estranha Visita (1962), dentre outros, além de poemas e crônicas. As novelas aqui referidas descrevem os equipamentos urbanos modernos, as multidões, os automóveis, os códigos, enfim, representativos de uma cidade que se tornaria uma metrópole nos moldes de uma cidade européia. Participante do grupo neo-simbolista gaúcho, companheiro de Mário Quintana, Theodomiro Tostes e Augusto Meyer, 
Reynaldo é um escritor que valoriza a musicalidade das palavras, o subjetivismo, ao mesmo tempo em que reflete sobre o movimento da sociedade urbana, incorporando à sua obra motivos e propostas temáticas do Modernismo (REMÉDIOS, 1994, p. 90).

Desenvolvendo uma narrativa marcadamente introspectiva, os personagens de suas novelas "são almas desesperadas debatendo-se no espaço urbano, em meio aos meandros da memória, que deixam emergir as esperanças, decepções, ideais, lutas, vitórias e frustrações enquanto percorrem um caminho na busca de valores que legitimem e justifiquem a existência do homem no mundo" (REMÉDIOS, 1992, p. 80).

Wilson Chagas aponta o destino do "personagem invisível" nas novelas de Reynaldo. Atraídos pelo imprevisto que os espera em algum lugar no tempo, seus "personagens vivem em situações extraordinárias, fora do comum, onde a casualidade dos encontros, um minuto antes ou depois, origina tragédias e situações desatinadas". (CHAGAS, 1976, p.75). Situados em ambientes noturnos, "por não agüentarem o sol forte da realidade" (ibidem, p.78) perambulam pelas ruas desertas, pelas casas de corredores escuros, às vezes escalando vertiginosos terraços de arranha-céus - tipologia do crescimento da cidade.

No início do século passado (1903-1904) o Rio de Janeiro, como é sabido, passa por um processo de urbanização (inspirado, aliás, no modelo arquitetônico parisiense) que, a partir daí, se propagou pelas demais capitais brasileiras. Interessante notar como já no final da década de vinte, a cidade de Porto Alegre dá início à trajetória de crescimento urbano, mais precisamente durante a administração do prefeito Alberto Bins, período em que são alargadas, e/ou abertas, vias que deram uma nova imagem à cidade, destacando-se, na área central, as avenidas Otávio Rocha, Borges de Medeiros e Senador Salgado Filho; e, ligando o centro da cidade aos municípios situados ao norte, a Avenida Farrapos. Neste período, os tipos de edificações variam e os edifícios de apartamentos aumentam em número e altura em Porto Alegre. Para a arquite- 
ta e pesquisadora Nara Machado, a verticalização dos prédios portoalegrenses, característicos das décadas de trinta e quarenta, surge como resultado do domínio no uso da tecnologia do concreto armado, e do elevador, pelos profissionais imigrantes alemães e nacionais (esses, muitas vezes, indo estudar no exterior) e com a instalação de importantes construtoras locais e de escritórios de empresas nacionais e multinacionais.

Paralelamente ao crescimento dos edifícios altos na cidade, a cultura e a literatura gaúcha nas duas primeiras décadas do século XX, e com maior intensidade nos anos 30, recebem grande impulso através da criação de cafés, confeitarias e bares na cidade, nos quais se discute política, literatura e modernidade. A Livraria do Globo liderada pelo escritor Érico Veríssimo na década de 30, transforma-se numa das maiores editoras brasileiras. Principal foco de reunião dos novos escritores e localizada na Rua da Praia, rua onde se concentravam os melhores hotéis, cafés, restaurantes, confeitarias e lojas de roupas da cidade, a Livraria reunia poetas como Theodemiro Tostes e Athos Damasceno, prosadores como Cyro Martins e Dyonélio Machado e críticos como Augusto Meyer e Moisés Velinho.

Segundo a pesquisadora Maria Luiza Ritzel Remédios, a prosa gaúcha, nos anos 20 e 30 do século $\mathrm{XX}$, apresenta duas vertentes: uma voltada para o problema social do homem do campo, e, outra que questiona o cenário social da cidade e o lugar do homem na coletividade, introduzindo, dessa forma, a cidade de Porto Alegre na ficção literária.Alguns historiadores apontam o romance Clarissa (1933), de Érico Veríssimo, como a primeira novela de representação urbana que tinha Porto Alegre como cenário; porém é somente a partir de 1935, com a publicação de $A$ Ronda dos Anjos Sensuais, de Reynaldo Moura, Caminhos Cruzados, de Érico Veríssimo, e Os Ratos, de Dyonélio Machado, que essa representação se torna mais consistente.

Também para a história da arquitetura da cidade, 1935 foi um ano importante, ano da realização da monumental Exposição do Centenário Farroupilha, que deslumbrou tanto visitantes locais como estrangeiros. Toda a 
área do atual Parque Farroupilha foi ocupada por grandes pavilhões de estuque provisórios, jardins e fontes; a cidade inteira se preparou para a realização desta grande exposição e, é esta cidade que se exibe que Reynaldo Moura apresenta em suas novelas. As descrições literárias conformam cenários ora imaginados, ora existentes de fato na cidade. Neles se desenrolam dramas e transitam os protagonistas urbanos modernos - carros, bondes e limusines nas novas avenidas, multidões nas ruas, edifícios cúbicos, arranha-céus e o som de motores de navios e aviões em movimento, sirenes do progresso e da modernidade.

Reynaldo descreve esta cidade durante o dia, sob o sol da manhã, invadida por pessoas comuns e apressadas; durante a noite, escura ou iluminada por néon, povoada por anjos vagabundos ou boêmios amargurados, e durante a madrugada deserta, chuvosa e silenciosa, cenário de encontros proibidos e misteriosos'

Na novela $A$ Ronda dos Anjos Sensuais publicada em 1935, a cidade colonial de Porto Alegre é representada pela personagem Neli, apelidada de "Miss Futebol" e nascida em 1926, das páginas de um número da revista "Máscara". Morena e curvilínea, "Neli é como uma polpa de um fruto do mato sazonado dentro do fulgor da sesta e da madrugada brasileira" (MOURA, 1935, p. 96). O que move sua ação como personagem principal feminina é o seu desejo de liberdade, de ser uma mulher independente e moderna como sua amiga alemã Charlote. Sob a alcunha de "vampiro loiro" e surgindo do mistério perfumado de uma existência inquietante de rapariga européia, essa amiga berlinense exerce uma profunda sedução em Neli. Representando a metáfora da modernidade importada estrangeira, há no íntimo de Charlote Benz "o resultado do trabalho infatigável de várias civilizações”. (CRUZ, 1994, p. 45). Essa existência inquietante se verifica através dos hábitos praticados por Charlote, pouco convencionais para a época: vive um caso homossexual amoroso, é usuária de cocaína e dirige tresloucadamente sua limusine Ford, último modelo. No final da novela, a morte da principal personagem feminina (Neli) aponta, metaforicamente, 
para o fim da cidade antiga e o nascimento de uma cidade nova, a cidade moderna.

Quanto aos variados cenários da novela, podese dizer que eles são reconhecíveis, "reais", mas é sobretudo no bairro Independência, onde se situa o palacete e onde moram a personagem principal, sua irmã e o cunhado escritor, que se desenrola grande parte da trama. Apesar de ser observada através da visão aristocrática, a cidade da novela não é resultado somente dessa visão, pois vêem-se descrições de ruas da zona central, com suas galerias e seus edifícios altos, de ruas e campo de futebol do bairro do Menino Deus, entre outros lugares reais da cidade.

Estes lugares, tipologias, praças e outros locais de encontro corresponderiam à cidade real, visto que, segundo Cláudio Cruz, "Porto Alegre sofria de uma fome de realismo que uma região, ainda não coberta literariamente, sentia na década de 30" (CRUZ, 1994, p. 27). Portanto, Reynaldo nomeia ruas, edifícios e praças reais, assim como relata certos eventos sociais realizados efetivamentee, àquela época, na cidade. No ano de publicação da obra, 1935, por exemplo, a exposição do pintor Leopoldo Gotuzzo realmente aconteceu na cidade; a livraria citada no decorrer da história é a Livraria do Globo; a galeria é a Galeria Chaves; o cinema é o Imperial e assim por diante. Todas edificações reais da cidade de Porto Alegre estão na trama romanesca.

O nascimento do edifício alto é relatado em vários momentos no texto, assim como a necessidade de vender essa modernidade através da propaganda colada nos tapumes da obra em construção:

Em poucos dias sobem as tábuas horizontais e escondem tudo como a tampa de um cofre. A inquietação dispersiva dos propagandistas enche de carnaval a madeira provisória. Pousa na construção cheia de pó a asa reta dos anúncios, e escorre em triângulos pela superfície vertical o sangue e o betume de letreiros e de cenários geométricos que parecem capas de revistas. (MOURA, 1935, p. 72) 
Ao olhar para a cidade ao entardecer, Reynaldo sai do contexto de Porto Alegre e compara as novas tipologias com outras modernidades arquitetônicas que sabe estar acontecendo em outros países, como o Construtivismo na Rússia, o Futurismo na Itália e o Surrealismo na França. "Pensa na construção de casas redondas pensa na Rússia telegráfica nas propagandas ilustradas. Casa com eixo. Cones. Cilindros lisos iluminados interiormente" (MOURA, 1935, p. 72).

Movimento ocorrido nos meios da arte russa do início do século, fundado em Moscow por Vladimir Tatlin, o construtivimso russo surge como uma decorrência do futurismo italiano e do cubismo francês. Adquire características próprias perseguindo o ideal de abstração: despoja-se de qualquer alusão à natureza. Rompe radicalmente com a arte do passado, com a representação do real e propõe uma nova linguagem plástico-pictórica. Inicialmente confinadas à escultura, as idéias do movimento rapidamente foram adaptadas, influenciando a arquitetura. Esta se caracteriza por utilizar as formas geométricas puras; grandes cilindros, cubos, cones, etc. Por volta de 1932, a desaprovação do regime soviético tinha colocado fim ao movimento, mas as suas idéias formais disseminaram-se pela Europa, influenciando a Bauhaus e o De Stijl. Ainda hoje se faz sentir a influência deste movimento em correntes como o deconstrutivismo e nas tendências high tech da arquitetura contemporânea.

Locomotivas devorando as dimensões do tempo, imóveis como cadáveres de alienados. O bar que é tombadilho. O bangalô que é torpedeira cintilando por todas as suas vidraças de mica. O palácio máquina urbana. É o filme em série. A cóca misturada com o cimento dos engenheiros modernos. (MOURA, 1935, p. 74)

Outra vanguarda artística alusiva à cidade moderna em que estava se transformando Porto Alegre, é o Futurismo. Na literatura, como é sabido, o movimento futurista (Marinetti) pregava a vida moderna, a aceleração da produção mecânica e a imagem da velocidade em ação: 
Afirmamos que a magnificência do mundo se enriqueceu de uma beleza nova: a beleza da velocidade. Um carro de corrida adornado de grossos tubos semelhantes a serpentes de hálito explosivo... um automóvel rugidor, que parece correr sobre a metralha, é mais belo que a vitória de Samotrácia. (Manifesto do Futurismo, 1908)

O Surrealismo mostra-se na obra do escritor gaúcho na medida em que compara a verticalidade do edifício que sobe na cidade às formas orgânicas, e os homens construtores a pequenos animais. Nessas descrições surrealistas, as imagens são obtidas através de manifestações onde a mente não exerce nenhum tipo de controle sobre a produção final. Nesse método, denominado automatismo, os artistas surrealistas ${ }^{1}$ tentam plasmar as imagens da realidade com o subconsciente. As preferências de Reynaldo pela fauna e pela flora são recorrentes em sua obra: ${ }^{2}$ : "As linhas claras do edifício que subiu como um jato acima de todos os terraços urbanos parecem a superfície de um grande caule perfurado pelos homens formigas" (MOURA, 1935, p.73).

A publicação seguinte de Reynaldo Moura Intervalo Passional, de 1944, coincide com o pico de crescimento populacional e construtivo da cidade de Porto Alegre. Conforme dados do IBGE, de 1940 a 1960, a população de Porto Alegre cresce de 275.000 para 641.000 habitantes e, segundo Célia Ferraz, de 1937 a 1945 ocorre o final do processo de modernização urbana, iniciado na década de 20 , na gestão Otávio Rocha.

O aumento da população da cidade é referenciado através da presença do transporte coletivo - o bonde - que convive, na paisagem urbana, com a limusine, as árvores das praças e os edifícios cúbicos. Nessa novela, o autor repete as associações orgânicas próprias do Surrealismo: a limusine é um enorme inseto iluminado e, o bonde, uma larva.

Ao longe a limusine corria e era um coleópterode pupilas inflamadas. Levava na frente um clarão oblongo que resvalava pelo solo. Os bondes de
${ }^{1} \mathrm{Na}$ arquitetura, destaca-se Antonio Gaudi, considerado, por muitos, como o segundo grande arquiteto surrealista. Claude Ledoux, que tirava da natureza suas formas decorativas, é considerado o primeiro arquiteto surrealista.

${ }^{2} \mathrm{Na}$ arquitetura, destaca-se Antonio Gaudi, considerado, por muitos, como o segundo grande arquiteto surrealista. Claude Ledoux, que tirava da natureza suas formas decorativas, é considerado o primeiro arquiteto surrealista. 
ventre iluminado pareciam deslizar como larvas. Discos verdes e vermelhos piscavam. E no mar resplandecente o volume negro das árvores, dos bosques da praça próxima, pareciam misteriosas ilhas de sombra. (MOURA, 1944, p.104)

Os bondes quando ela passava pelo centro, eram como losangos amarelos de atordoamento, as limusines resplandeciam um instante seccionando arestas de sol nas avenidas e o alto dos arranha. céus se inflamava levemente de violeta sob o va、 por malva imobilizado no primeiro plano do céu. Entrava em contato com a multidão e sentia cheiro de gente. (ibidem, p. 136)

A novela Intervalo Passionalsitua personagens em um edifício alto denominado "Excelsior", que anos mais tarde seria construído em Porto Alegre. O autor detalha a conformação espacial cúbica do edifício com elevador no centro, sua altura, e a presença de um terraço onde os protagonistas admiram o movimento dos transportes, a propaganda aérea e ouvem a sirene no rio encantados pela altura, inebriados pela paixão.

Um vapor luminoso subia no ar transparente. Ouviram o uivo de uma sirene nas luzes vacilantes do rio. Sobre os arranha-céus brancos que se destacavam na penumbra dourada e pareciam enormes cubos de mármore, os anúncios palpitavam se extinguiam. Um pneumáticogigantesco girava no céu. Era uma roda de rendilhado fogo azul e em torno as letras violáceas iam surgindo, uma a uma, até formarem a palavra completa. Depois desapareciam. Azul violeta. Verde, azul, vermelho. Sobre o terraço do Excelsior o vento passava. Edgar agachou-se junto ao parapeito para reacender o charuto. (ibidem, p.109)

Reynaldo, através da personagem feminina, observa o edifício em construção e o declara soberano em uma imagem de cidade que, além de estar subindo vertiginosamente, possuía também uma movimentação aérea já consolidada. No ano de 1933, a VARIG, para basear seus vôos no 
Rio Grande do Sul, passou a utilizar o espaço que pertencia ao Serviço de Aviação da Brigada Militar. Em 1940 foi construído o primeiro terminal de passageiros de Porto Alegre, o "Aeródromo de São João" que, em 1951, passou a ser designado "Aeroporto Internacional Salgado Filho". Nesta passagem do texto, o arranha-céu em construção invade um espaço até então reservado aos aviões. Esse espaço alto, ao mesmo tempo que o recebe, coloca-o em risco:

Uma vez enquanto esperava o bonde no abrigo para ir à casa da mãe, Verônica ficou olhando um arranha céu em construção. $O$ esqueleto de cimento se empinava no espaço, se destacava objetivo, imperioso, na poeira do ar azulado. Às vezes, quando seus olhos se fatigavam de olhar, parecia que balançava que o vento do alto - vento de loucos aviões, tufões de hélices, ventosa do vácuo - parecia que o vento o embalava perigosamente. (ibidem, p.174)

Muitos edifícios de apartamentos foram construídos em Porto Alegre no século Xx a partir desta matriz compositiva: o edifício de forma cúbica em que a circulação vertical se estabelece no meio do volume; no miolo central localiza-se o elevador e, ao seu redor, as escadas de serviço. Acima, no terraço, as engrenagens do elevador, tartarugas negras.

Subiram sozinhos mais seis andares no elevador. Penetraram nos compartimentos de serviço do Excelsior. Os corredores envolviam o tubo quadriculado do ascensor. Havia escadas desertas por onde o silêncio ativo se estendia. Era a tranqüilidade impessoal dos lugares mecânicos, o outro lado do conforto. No ultimo piso as máquinas do ascensor trabalhavam solitárias, um rumor abafado se desprendia das tartarugas negras dos dínamos. Lâmpadas tristes derramavam uma claridade de necrotério.

Erguiam os olhos e então, separados da terra, tendo apenas a noção da presença do terraço que às vezes parecia oscilar levemente como um 
tombadilho, sentiam-se suspensos, dir-se-ia que o Excelsior flutuava no mar da noite, que estavam isolados entre constelaçōes. (ibidem, p. 105)

Quando Reynaldo Moura publicou a novela $O$ Poder da carne, em 1954, a tipologia do edifício alto já era recorrente na cidade e parecia conviver amigavelmente com seus elementos naturais. Em 1954 já estavam construídas edificações modernistas monumentais e significativas na cidade, as Tribunas Sociais do Jockey Club do Rio Grande do Sul (1952), o Palácio da Justiça (1953) o Edifício multifuncional Jaguaribe (1952), o Edifício Esplanada (1952) dentre outros.

Ampla, a janela do apartamento mostrava o mundo parado, a cidade repousando lá em baixo numa distância de nove andares, deitada junto ao rio. Edifícios surgiam das ruas escondidas, altos, truncando o horizonte que se esfumava, longe. Das ilhas subia um vapor que tornava o ar opaco. Um rebocador ia passando pelo meio do rio. (MOURA, 1954, p.45)

Reynaldo son ha contemplando a cidade sonolenta onde os edifícios têm cor prata e as ruas são azuis. Percebe os barulhos da cidade, vozes da movimentação dos motores dos transportes na cidade amanhecendo.

Há muito tempo, em certas madrugadas, contemplara os cimos da cidade. $\mathrm{O}$ alto dos arranha-céus mudava de cor, parecia alumínio. Em baixo a ligeira bruma azulava as ruas. Às vezes, ao despertar, evocava essa visão. Ficava ouvindo da cama o rumor distante de motores, como um rolar interminável. De vez em quando distinguia um motor isolado na enseada, outro suspenso no ar, no seio de um avião que chegava ou partia. Apitos de vapores... Em torno existia as cidades invisíveis, distribuídas em semicírculos pelas fronteiras de sua preguiça. (ibidem, p 59)

O Primeiro Plano Diretor de Porto Alegre, de 1954-59, elaborado nos moldes da Carta de Atenas, previa a implantação dos edifícios sobre pilotis e recuados em 
relação ao passeio público e aos lotes lindeiros. Isso não ocorreu na zona central da cidade pela dificuldade de implantar o recuo de jardim. Reynaldo descreve, então, as ruas como canais sombrios, com muitos edifícios altos formando labirintos. As galerias que fazem parte de alguns edifícios, construídos no centro, são mencionadas como árvores urbanas que protegem pedestres:

Ficou esperando sob as árvores urbanas. Automóveis passavam em silêncio. Na primeira oportunidade atravessou a pista ainda lustrosa da chuva rápida que caíra. Foi caminhando depois ao longo da ruazinha estreita. Muito altos os edifícios tornavam sombrio este local da cidade. (ibidem, p.53).

Elka vai meio oculta pela multidão, na rua profunda entre cubos cinzentos de edifícios. No alto daquele volume pardo que sobressai há uma frecha de claridade inclinada, mas o fundo do canal urbano é sombrio. (ibidem, p 96)

Para o personagem, a multidão é assustadora. Ali, no meio de pessoas apressadas, ele se sente perdido em um turbilhão formado por gente anônima e rodeado de edificações. Sente-se ameaçado por uma multidão que, junto aos edifícios cinzentos, contribui para aumentar seu desespero, na busca de provas para incriminar ou inocentar sua esposa Elka:

Começou a sentir a existência monstruosa das multidões, um ser inumerável na coesão de um momento. A torrente humana das ruas, o mar de máscaras anônimas pelos canais da cidade, nos labirintos dos edifícios. (ibidem, p 59)

Vai caminhando pela rua, no fundo do canal urbano, entre verticais cores de cinza dos edifícios, no meio do formigueiro escuro da multidão humana. Apurou o passo. O rumor da multidão em torno. A multidão de sombras passando, passando no canal profundo da rua, os robots deste mundo. (ibidem, p 165) 
Em 1954 ainda existiam edifícios enormes e antiquados em Porto Alegre, cenários das novelas de Reynaldo Moura. O edifício de elevadores antigos, com suas lojas e seus cafés, pelos quais circulavam pessoas simples, de status social diferente do personagem, seria, provavelmente, um prédio de apartamentos destinados a encontros misteriosos.

Era um prédio enorme e já antiquado. No piso térreo, pequenas lojas, barbearias, cafés de ínfima classe. Atravessou a porta larga, o hall de mosaicos sujos. O ascensor ia subir. Acomodouse entre pessoas desconhecidas. A cabina velha rangia, subindo, lenta. Um cheiro de roupa suada, de suor seco, de vidas sem banho, em torno. (ibidem, p.73)

Volta a visão surrealista de edifícios submersos, plasmados no entardecer da paisagem próxima ao rio, possuindo como substância envolvente a albumina, uma substância viscosa encontrada no soro do sangue e líquidos de organismos animais e vegetais. A cidade dos edifícios cúbicos, à noite, parece morta de tão silenciosa, não fosse o vento soprando no rosto da personagem feminina.

Os cubos dos edifícios os cubos do edifício pareciam túmulos, pareciam túmulos. Longe, a ense ada palpitava obscura. Um mundo morto de volumes submersos numa albumina azulada. Começava a existir o frio das horas tardias, e sobre o cimo dos edifícios as estrelas estavam mais próximas. Ela inclinava o rosto no vento do alto como se o encostasse amorosamente às espáduas da noite. (ibidem, p.171)

A última novela estudada neste artigo, Uma estranha visita, publicada em 1962, desenvolve-se em um curta temporalidade: das dezenove horas até a meia-noite do mesmo dia. No decorrer desse período, o personagem Felipe, ao tentar se livrar do corpo da amante morta aci- 
dentalmente em sua casa, morre em um acidente de automóvel. A hora final é marcada pela chegada do vôo que sua esposa havia tomado no Rio de Janeiro em direção a Porto Alegre e corresponde à hora exata da morte de Felipe no acidente. $O$ personagem, enquanto perambula pelas ruas molhadas da cidade, com o corpo da amante dentro do carro, angustiado, tem a sensação de ter perdido o controle de si mesmo, desconhecendo a rua, a cidade e até mesmo sua própria vida.

O narrador descreve o movimento da cidade que aumenta ao entardecer, momento em que as repartições públicas e os estabelecimentos comerciais fecham e são invadidos por multidões. A multidão anônima desperta, no personagem principal, sentimentos de identificação e, ao mesmo tempo, de repulsa por saber ser parte dela.

O momento do entardecer em cidades que dentro de nossa memória parecem de sonho. O pensamento obscuro no fundo de tantas insônias. Toda esta vida mascarada do mundo... Estava sentindo idiota a multidão sempre, sempre passando. Era um certo ódio meio sem direção. No fundo sabia que era contra aquela inesgotável multidão de figuras existindo e desaparecendo no infinito cotidiano da rua. Passavam, passavam, existiam um momento e se renovavam sempre, e sempre eram as mesmas. (MOURA, 1962, p.50)

O edifício, neste relato, possui trinta andares, e seu terraço é palco de um acidente: a protagonista feminina cai de um dos andares. O autor descreve o espaço como um protagonista, uma ventosa prestes a sugar alguém, um espaço que "entra em pânico", um agente responsável pelo desenrolar da trama, um espaço enclausurado nas paredes negras da cidade:

Estavam junto ao parapeito e ele tornou a espichar o pescoço e olhou para baixo. Na distância vertical de trinta andares o espaço era uma ventosa, e nessa mistura de noite e chuva com o asfalto lá longe, lá em baixo como o fundo de um 
canal velado, tinha a impressão de que o enorme edifício balançava num jogo de tombadilho. Na vertical, parecia que o espaço entrava em pânico. (ibidem, p.11)

Longe, longe, lá em baixo entre a névoa da chuva, como um cenário vertical de paredes negras e luzes no asfalto, o fundo da cidade na distância. Os automóveis pareciam mais longos, e deslizavam num silêncio de goma. Lá embaixo uma vida estranha, lenta e incoerente, estava submersa no fundo da vertigem. (ibidem, p.12)

Caminhando pela cidade, o narrador de Reynaldo Moura descreve o edifício que já constituía uma tipologia típica do centro da cidade, um prédio que abrigaria serviços diversos no térreo, além de lojas e quadros indicadores, escritórios e apartamentos anônimos no corpo do edifício.

Recomeçou a andar vagarosamente pelas imediações. Ia se desviando dos outros sem prestar atenção, sombras sem rosto. Espichava o olhar agudo para dentro das lojas. Havia também pórticos de arranhacéus que aglomeravam lá em cima escritórios, consultórios médicos, apartamentos anônimos, todo um mundo invisível que não se podia adivinhar da rua, é só entrando em cada hall e examinando os enormes quadros indicadores. (ibidem, p.49)

Reynaldo Moura foi um escritor talentoso que construiu sua obra atento às transformações que ocorriam no mundo, na sociedade e na cidade onde vivia. Desde sua primeira publicação, em 1935, a que mais representou a transformação da cidade de Porto Alegre provinciana em uma cidade moderna, suas descrições literárias revelam cenários ricos em equipamentos urbanos e elementos de arquitetura que indicariam uma modernidade emergente. Aquele ano de 1935 havia sido um marco para o desenvolvimento da capital gaúcha, com a exposição que projetaria a cidade nacionalmente e um marco literário a partir da publicação das obras de romancistas mencionados no início deste artigo. 
As avenidas molhadas na noite chuvosa onde máquinas poderosas, os automóveis, os bondes, deslizam na noite, as ruas estreitas com edifícios altos cúbicos como túmulos, a cidade imersa em névoa e albumina como se fosse um ser vivo adormecido, o néon invadindo o céu de Porto Alegre constituem o típico cenário do filme noir americano. Cabe ressaltar a potencialidade de o texto de Reynaldo ser adaptado para a narrativa fílmica, pois parece que o autor escreve como estivesse montando quadros para um roteiro cinematográfico.

Os acidentes automobilísticos - tragédias freqüentes nas novelas do escritor - representam, metaforicamente, a força da máquina e a impotência do homem perante o progresso, o qual provoca efeitos traumáticos nos personagens, como paralisias, desfigurações faciais e perda de memória.

A presença de personagens estrangeiros, em suas novelas, é bastante constante, uma mulher alemã, Charlote, em A Ronda dos Anjos Sensuais, ou uma francesa, Simone, em Um rosto noturno. Esses personagens, fortes em suas narrativas, são indicativos das diversas influências estrangeiras trazidas pelos arquitetos do velho mundo, que, fugindo de conturbações políticas de seus países, estabeleciam-se em Porto Alegre, empregando-se em diversas construtoras da cidade. Reynaldo reconhece essas influências arquitetônicas ao descrever o formato e a linguagem dos novos edifícios, cubos, cilindros iluminados.

À maneira de associações surrealistas, o autor exalta a velocidade dos automóveis e dos transportes coletivos e traduz uma capacidade de observação própria da sua condição de escritor, que se percebe nas descrições das edificações, das avenidas e dos ambientes noturnos iluminados pela luz do progresso. Ao descrever as tipologias dos edifícios, comparando-as, o romancista gaúcho reconhece a importância de estar conectado com o.que estava se passando no exterior, nos EUA, na Europa, em cidades que serviriam de parâmetros para as nossas transformações urbanas como Berlim e Nova York.

Intelectual que deixou uma obra pouco reconhe- 
cida de méritos na história da literatura gaúcha, Reynaldo Moura traduziu a memória da cidade de Porto Alegre através das suas descrições literais e imaginárias dos ambientes e edifícios modernos. Ao misturar fantasia e realidade, revelou as transformações, os anseios e os sonhos de uma sociedade que assistia à chegada de uma modernidade que prometia um progresso urbano e social inquestionável. Reynaldo, como escritor, cumpriu seu papel, pois nos legou uma rica memória social. Creio que já é tempo de nossas instituições acadêmicas reconhecê-lo como um importante e talentoso escritor cuja obra revive, simbolicamente, a história cultural da cidade de Porto Alegre nas primeiras décadas do século passado. 


\section{Referências}

BELO, Helton Estivalet. O Ecletismo e a Imagem da cidade: caso Porto Alegre. Porto Alegre: UFRGS, 1997.

BORDINI, Maria da Glória (organizadora). Centro Cultural CEEE Erico Veríssimo: memória que gera cultura, cultura que gera memória. Porto Alegre: CCCEV, 2002.

CRUZ, Claudio. Literatura e Cidade Moderna Porto Alegre 1935. Porto Alegre: EDIPUCRS, 1994

MACHADO, Nara. Modernidade, arquitetura e urbanismo: o centro de Porto Alegre (1928-1945). 1998. Tese (Doutorado)

- PUC - IFCH, Porto Alegre, 1998.

MONTEIRO, Charles. Porto Alegre: Urbanização e

Modernidade A construção do espaço social do espaço urbano. Porto Alegre: EDIPUCRS, 1995.

MOURA Reynaldo. Intervalo Passional. Rio de Janeiro: Livraria José Olympio Editora, 1944.

. O Poder da Carne. Porto Alegre: Livraria do Globo. 1954. - A Estranha Visita. Porto Alegre: Livraria do

Globo, 1962.

. A Ronda dos Anjos Sensuais. Porto Alegre:

Columbia, 1935.

SPALDING,Walter. Pequena História de Porto Alegre. Porto Alegre: Livraria Sulina Editora, 1967.

REMÉDIOS, Maria Luísa. Reynaldo Moura e o Romance no Rio Grande. Porto Alegre: Letras de Hoje. Edipuc, v. 29, n.3, 1989. - Maria Luíza. Reynaldo Moura: A Verdade, a Memória e a Invenção. Porto Alegre, Letras de Hoje. Ẻdipuc, v. 27, n.1, 1992. - Maria Luíza. As instâncias do sujeito em Érico Veríssimo e Reynaldo Moura. Cadernos do Centro de Pesquisas Literárias da PUC, Porto Alegre, v.1 n.4, 1995.

SANHUDO, Ary Veiga. Porto Alegre crônicas da minha cidade. Porto Alegre: Movimento, 1975

TOSTES, Theodemiro. Nosso Bairro. Memórias. Porto Alegre: Fundação Paulo do Couto Siva, 1989.

ZILBERMAN, Regina. Literatura Gaúcha temas e figuras da ficção e da poesia do Rio Grande do Sul.Porto Alegre: L\&PM, 1985. 